Proceedings of the Creative Construction Conference (2018)

Edited by: Miroslaw J. Skibniewski \& Miklos Hajdu

DOI 10.3311/CCC2018-093

Creative Construction Conference 2018, CCC 2018, 30 June - 3 July 2018, Ljubljana, Slovenia

\title{
The relationship of risk assessment with project success: an empirical study of small and medium contractors in Gauteng, South Africa
}

\author{
Berenger Yembi Renault ${ }^{\mathrm{a} *}$ and Nazeem Ansary ${ }^{\mathrm{b}}$ \\ ${ }^{a^{*}, a \& b}$ Dept of Construction Management \& Quantity Surveying, University of Johannesburg, Cnr Siemert \& Beit Streets, Doornfontein, 2028, \\ Johannesburg, South Africa
}

\begin{abstract}
Risk assessment (RA) is widely acknowledged to be linked with construction project success (PS). However, there is a lack of empirical evidence to support this perception. Therefore, the current study sought to fill the gap by establishing the relationship of RA with project success. A structured questionnaire was used to collect data from small and medium contractors (SMEs) who were conveniently sampled in Gauteng, South Africa. The data was analysed using the Statistical Package for the Social Sciences (SPSS) version 23, computing inferential statistics. The results revealed a statistically significant relationship between RA and PS; that PS was positively influenced by RA. This was an indication that RA in construction is an important risk management factor that enhance project management decision making and hence influence PS. This finding contributes to the body of knowledge on the subject of RA and management and provide guidance to contractors on the practical implementation of RA concerns for construction PS.
\end{abstract}

(C) 2018 The Authors. Published by Diamond Congress Ltd., Budapest University of Technology and Economics Peer-review under responsibility of the scientific committee of the Creative Construction Conference 2018.

Keywords: Contractors; project success;relationship; risk assessment; South Africa

\section{Introduction}

Successful completion of project in construction is the most desirable for all organizations and involved stakeholders. Project success or failure in construction have long been themes of interest among researchers this, for over the past 20 years. Reference [1] indicated that a construction projects is said to be a failure when it failed to be delivered within predefined project objectives which include: deliver the project within the scheduled time, estimated project cost, achieving desired quality, and without accident or injury (Health and Safety). Failures could threaten the very existence of the company [2]. It was indicated in a report released by reference [3] that, on average construction projects ran $45 \%$ over estimated cost and $7 \%$ over scheduled delivery time, while delivering $56 \%$ below desired quality. It was further reported that only $12 \%$ of construction projects had finished on time and within the established budget. Reference [3] elaborated on depressing construction project failure rates between 50\% and 70\%. These findings are inclusive of projects undertaken by construction small and medium enterprises (SMEs). Reference [2] confirmed that the risk of not delivering the project within its set target in SMEs was higher than in larger enterprises. Studies conducted, revealed that many SMEs fail due to the lack of access to finance [1]; [4]; [5]. However, a study conducted by reference [6], revealed several factors explaining the high failure rate of construction SMEs among which risk management was one of the important factors that affected project success. Risk management is the process by which risks are identified, assessed and mitigative measures are formulated in order to minimize the adverse impact of risks on project objectives. Reference [4] indicated that risk assessment was one of the most important phases of the risk management process that risk assessment when conducted, increases the likelihood of project success. Furthermore,

Corresponding author: renault08@yahoo.fr 
Reference [7] argued that the adoption of risk assessment and management practices are closely aligned with overall project performance. Reference [8] indicated that the poor delivery of South African construction projects was exacerbated by poor management and inefficient risk management application. Although there was high importance of risk assessment to construction project success, the adoption of these risk assessment methods in construction projects is inconsistent, especially among SMEs [6]. Lack of adoption of risk assessment could have a negative impact on the overall performance of construction organisations in South Africa, given that, as pointed out by references [8], and [9], some construction SMEs in South Africa do not implement risk assessment and management techniques as part of managing their projects. One of the probable reasons for the lack of adoption of risk assessment within the South African construction industry, especially among construction SMEs, has been the scarcity of empirical studies examining the relationship of risk assessment with construction project success. Therefore and based on the above observation, the current study aims to establish relationship of risk assessment with project success of construction SMEs.

\section{Literature review}

\section{Criteria of project success}

Reference [10] define a project as the accomplishment of a stated objective, which encompasses a sequence of activities and responsibilities that require resources. The Oxford Dictionary considers criterion as a standard or principle by which something is judged, or with the support of which a decision is reached. The Oxford Dictionary further explains success as an advantageous outcome or the acquisition of fame or prosperity. When merging these two notions, criteria of project success can be regarded as the set of principles by which advantageous outcomes can be accomplished within a set specification. Reference [11] posited that project success means different thing to different people. Reference [12] regard success as an imperceptible sensitive sentiment, which changes with dissimilar management outlooks, and with the stages of the project. Contractors, sub-contractors, designers, consultants and owners have specific criteria for assessing success. For instance, architects usually value aesthetics rather than building cost as the leading criterion for success. However, the client may consider other measures more. Additionally, even the same person's perception of success can vary from project to project.

\section{Project Success measures}

Over the years, numerous studies have been conducted on project success, and most of them have suggested various dimensions for measuring project success. Reference [11] opined that project success is contrastingly viewed among researchers and practitioners. The conventional measures of time, cost, and quality known as the Iron triangle have been the leading success metrics in construction [13]. The Iron triangle is cited in nearly every study [14]; [15]; [16]; [17] on project success. Contrariwise, reference [18] posited that project success should not be limited to just the Iron triangle and the project management community need to be informed about this. Reference [13] indicated that while other definitions of project success have emerged, the iron triangle is constantly cited in the unconventional definitions.

In addition to the conventional measures, reference [19] supported that dimensions for project success should also encompass project psychosocial outcomes which involve the contentment of interpersonal relations with the project team. Individual dimensions such as participants' satisfaction level are referred to as soft dimensions. The incorporation of satisfaction as a success metric is recommended by reference [20]. Furthermore, reference [21] suggested incorporating the absence of legal claims as a measure of project success. This indicates the importance of including safety as a success measure since it is logical to anticipate that if accidents materialise, both clients and contractors may be subject to financial loss, contract delay as well as legal claims. Reference [22] assessed project success extensively based on five criteria namely; maintenance cost, construction cost, time, safety and flexibility to users. Reference [23] stated that it is problematic to evaluate whether the performance of a project is a success or a failure owing to the fact that the notion of success remains unclear amongst project participants. According to [24], the project is a complete success if it attains the technical performance specifications to be executed, and if there is satisfaction regarding the project outcome among key users and project team members. In evaluating project success [25] included a range of criteria which included project meeting planned cost, time, quality of work, affability of the environment, transfer of technology, client and project manager's satisfaction, and health and safety. Reference [25] defined project success based on four measures namely; achieving design goals, the value to the end user, the value to the organisation, the value of the technological infrastructure of the country and of organisations implicated in the development process. All these measures combined together provide the inclusive evaluation of project success. 
Regardless of the controversy in defining project success, this study follows the definition of project success as per [26]; [22]; [17]. This implies that the measures used in the study reflect project performance [14]; [15]. Reference [17] posited that the utilisation of a set of project success measures gives a considerable evidence of project performance than focusing on a single measure or a minor number of unplanned measures.

\section{Conceptual framework for the study}

Figure 1 represents the theoretical conceptual framework proposed in the study. The framework depicts the influence of the factor to project success as well as the hypothesized relationship between the constructs. On the other hand, project success is dependent on the level of practice of the factor namely; risk assessment. 1) determine the risk cause, duration, and volatility; 2) determine the probability of the risk occurring, impact, and classification consistency; 3) Establish the risk profile; 4) Assess risk by quantitative analysis methods; and 5) Assess risk by qualitative analysis methods were employed as the variables of project risk assessment. The relationship between the variables is discussed in the next section. For project success, reference [19] maintained that time, cost and quality have been the leading success metrics of construction projects. However, references [22]; [23] posited that project success should not be limited to just the traditional view. Reference [26] further suggested incorporating the absence of legal claims as a measure of project success. This indicates the importance of including safety as a success measure since it is logical to anticipate that if accidents and/or injury materialise. For the purpose of this study, time, cost, quality and health and safety were used as project success variables.

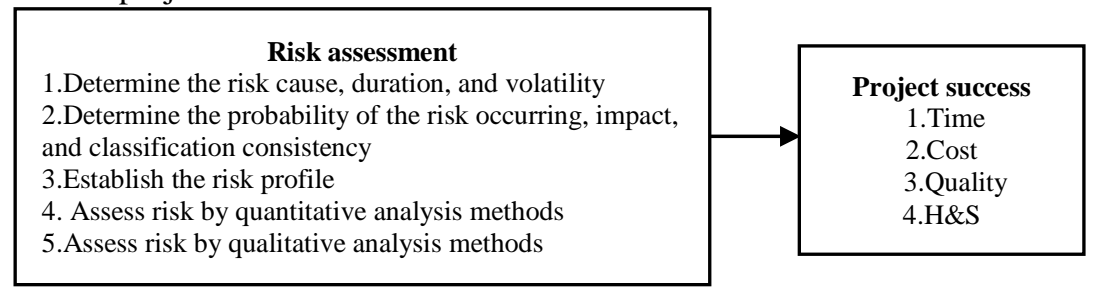

Fig 1. Conceptual framework

\section{Relationship of risk assessment with project success}

Reference [27] established that risk assessment activity makes a greater significant impact on the success of the project. The results indicated that adopting risk assessment has a substantial positive impact on project success as project staff was able to take actions to mitigate the occurrence of risks to a greater extent. Reference [28] tested the relationship between risk assessment and planned budget. The author established that there was an impact of risk assessment on project planned budget. In order to abate the rise of unsuccessful project completion in construction, the importance of risk assessment is a fundamental factor in an organisation risk management practices as emphasized by several authors [2]; [29]; [30] who affirmed the influence of risk assessment on the successful completion of a project. They reported that assessing uncertainties during the project, making use of the RM strategies and understand the business environment, significantly impact on project outcome. By assessing risk, managers can distinguish between acceptable and unacceptable risk events, and as a result enable them to capture and process information to assist them in the development of a risk management strategy [31]; [32]. Likewise, reference [33], indicated that risk assessment once performed, improved project objectives, accurate schedule, improved communication between relevant parties, and hence increased the chance of project success [33].

\section{Methodology}

The population of the study comprised of top management of SMEs (mostly owners, owner-managers, managers and project managers) who were selected from the Construction Industry Development Board (CIDB) register of contractors. In identifying potential respondents, the researcher ensured that all respondents were graded 1 to 6 (indicating small and medium contractors) and that they had a valid registration with the body they were from in order to participate in the study. Both secondary and primary data were used in the study. An extensive review of literature was carried out to gather secondary data included in the questionnaire which was later pre-tested. Primary data on the other hand was collected by administrating a questionnaire, via personal hand delivery method.

The survey consisted of forty-two statements/measures addressing nine risk management factors of which risk 
assessment comprised of five statements/measures. Following the questionnaire pre-testing, the final refined version of the questionnaire was distributed to 225 conveniently sampled SMEs using personal hand delivery and collect method of which 187 questionnaires were returned of which 6 were excluded from the study due to various ambiguity (questionnaire incorrectly answered, respondents' information missing and inadequate information provided). Consequently, the remaining 181 questionnaires were deemed usable representing approximately $80 \%$ response rate.

SPSS version 23 was employed computing descriptive statistics, Exploratory Factor Analysis (EFA) and Multiple Regression Analysis (MRA). EFA was performed to gather information about the uni-dimensionality of the variables, to confirm their validity and reliability using Oblimin with Kaiser Normalisation rotation and to assess the strength of the interrelationship among the variables. MRA was conducted to ascertain the relationship of monitoring and review with project success by determining the influence monitoring, review and continuous improvement on project success.

The measurement instrument was also tested for validity and internal consistency. Validity was ensured as a result of conducting an extensive literature review by consulting previous related studies, this was requisite to specify the variables. The questionnaire was reviewed and revised by experts (academics, researcher's promoter, and a professional statistician) before the pilot study took place. Internal consistency was tested using Cronbach's Alpha. A generally agreed upon minimum limit for Cronbach alpha is 0.70 [34]. However, a cut-off value of 0.60 is common for exploratory research and values closer to 1 suggest good reliability [35]. For this study, a cut-off value of 0.60 was adopted as used by [34].

\section{Results and discussion}

This section of the study reports on demographics, exploratory factor analysis and multiple regression analysis results. Descriptive statistics were used to analyse the profile of the respondents and the company. Exploratory Factor Analysis (EFA) was used to gather information about the unidimensionality of the variables. Multiple Regression Analysis (MRA) was used to determine the influence of risk assessment on project success.

\section{Demographic results}

Results revealed that among the respondents, $81.80 \%$ was male while $18.20 \%$ was female, $87.56 \%$ were either owners or manager of their enterprise, $56.40 \%$ were African/Black, had either matriculation (22.70\%) or a certificate $(20.40 \%), 43.10 \%$ of respondents had 10 years' or less experience in construction. Furthermore, it was found that $37.60 \%$ of SMEs were subcontractors or general contractors (31.50\%), working mostly in Johannesburg (41.40\%) and Tshwane $(30.90 \%)$ Metropolitan Municipalities. Nevertheless, the subcontractors either operated for the main contractor or were sole trade contractors.

\section{Results from EFA}

Risk assessment was subject to EFA using SPSS version 23 which was used to gather information about the unidimensionality of the variables as well as to evaluate its reliability, discriminant validity and convergent validity. The Cronbach's Alpha of each measure ranged from 0.892 to 0.908 with an overall Cronbach's alpha value of 0.908 (Table 1). These results were all greater than the recommended value of 0.6 which indicated good reliability [36].

Table 1. Cronbach's Alpha of risk assessment measures

\begin{tabular}{|l|l|l|}
\hline Code & Risk assessment measures & $\begin{array}{l}\text { Cronbach's } \\
\text { Alpha (0.908) }\end{array}$ \\
\hline RA1 & I/We determine the risk cause, risk duration, risk volatility. & 0.890 \\
\hline RA2 & $\begin{array}{l}\text { I/We determine the probability of the risk occurring, the impact, classification } \\
\text { consistency, i.e. high/medium/low }\end{array}$ & 0.892 \\
\hline RA3 & $\begin{array}{l}\text { I/We establish the risk profile e.g. high probability/high impact, high } \\
\text { probability/low impact. }\end{array}$ & 0.871 \\
\hline RA4 & $\begin{array}{l}\text { /We assess risks by quantitative analysis methods e.g. Probability, sensitivity, } \\
\text { scenario, simulation analysis. }\end{array}$ & 0.875 \\
\hline RA5 & $\begin{array}{l}\text { //We assess risks by qualitative analysis methods e.g. Direct judgement, comparing } \\
\text { option, descriptive analysis. }\end{array}$ & 0.908 \\
\hline
\end{tabular}

Results of correlation matrix coefficient in Table 2 revealed that the coefficient ranged from 0.478 to 0.756 . They were all greater that the suggested cut-off value of 0.30 , indicating that the four measures (RA1, RA2, RA3, RA4, and RA5) were good measures of the factor. These values were all above the recommended value of 0.60 , suggesting good reliability [34] 
Table 2. Correlation matrix for risk assessment measures

\begin{tabular}{|c|c|c|c|c|c|c|}
\hline \multicolumn{2}{|c|}{} & RA1 & RA2 & RA3 & RA4 & RA5 \\
\hline \multirow{4}{*}{ Correlation } & RA1 & 1.000 & & & & \\
\cline { 2 - 7 } & RA2 & $\mathbf{0 . 7 5 6}$ & 1.000 & & & \\
\cline { 2 - 8 } & RA3 & $\mathbf{0 . 7 0 0}$ & $\mathbf{0 . 6 8 4}$ & 1.000 & & \\
\cline { 2 - 8 } & RA4 & $\mathbf{0 . 6 9 7}$ & $\mathbf{0 . 6 8 3}$ & $\mathbf{0 . 7 7 1}$ & 1.000 & \\
\cline { 2 - 8 } & RA5 & $\mathbf{0 . 4 7 8}$ & $\mathbf{0 . 4 7 9}$ & $\mathbf{0 . 7 1 5}$ & $\mathbf{0 . 6 8 4}$ & 1.000 \\
\hline
\end{tabular}

The KMO measure of sampling adequacy in Table 3 was 0.849 which was above the cut-off value of 0.6. Furthermore, Bartlett's Test of Sphericity was statistically significant at $\mathrm{p}=0.000(<0.05)$, supporting the factorability of the correlation matrix [35]. These results indicate the factorability of the data set.

Table 3. Test of data factorability

\begin{tabular}{|l|l|l|}
\hline \multicolumn{2}{|l|}{ Kaiser-Meyer-Olkin Measure of Sampling Adequacy } & 0.849 \\
\hline Bartlett's Test of Sphericity & Approx. Chi-Square & 629,155 \\
\cline { 2 - 3 } & df & 10 \\
\cline { 2 - 3 } & Sig. & 0.000 \\
\hline
\end{tabular}

Results of EFA further evinced that of the five measures expected to measure risk assessment, only one measure had an eigenvalue above 1 (3.669). It explained $73.38 \%$ of the variance and accounting for $73.38 \%$ of the total variance. Since only one component was extracted, the solution cannot be rotated as it shows that this component is meaningful and it defines only a one-dimensional component as indicated by reference [37]. Therefore, sufficient evidence of convergent validity was provided for this construct.

Table 4. Percentage variance explained-risk assessment

\begin{tabular}{|l|l|l|l|}
\hline Component/Item & Eigenvalue & \% of explained Variance & Cumulative \% \\
\hline 1- RA1 & $\mathbf{3 . 6 6 9}$ & $\mathbf{7 3 . 3 7 9}$ & $\mathbf{7 3 . 3 7 9}$ \\
\hline 2- RA2 & 0.635 & 12.695 & 86.074 \\
\hline 3- RA3 & 0.251 & 5.013 & 91.087 \\
\hline 4- RA4 & 0.236 & 4.720 & 95.807 \\
\hline 5- RA5 & 0.210 & 4.193 & 100.000 \\
\hline
\end{tabular}

In addition, the decision to retain only one component was based on Kaiser's criterion by looking at eigenvalues greater than 1. Using Catell's (1966) scree test, it was decided to retain one component for further investigation. This was further supported by the results of principal axis factoring which revealed that the four measures loaded strongly together on one component. Their factor loadings presented in Table 5, were greater than the recommended value of 0.40 , as suggesting by references [35]; [36].

Table 5. Component matrix for risk assessment measures

\begin{tabular}{|l|c|}
\hline \multirow{2}{*}{} & Component \\
\cline { 2 - 3 } & 1 \\
\hline RA3 & 0.900 \\
\hline RA4 & 0.899 \\
\hline RA1 & 0.850 \\
\hline RA2 & 0.843 \\
\hline RA5 & 0.777 \\
\hline
\end{tabular}




\section{Hypothesised relationship}

The relationship between project success and risk assessment was hypothesised based on the results from EFA in support with reviewed literature. The null (Hypothesis 0 ) and alternative hypotheses (Hypothesis 1), which were tested using multiple regression analysis, include the following:

Hypothesis $1_{0}$ : Risk assessment does not influence project success; and

Hypothesis 1: Risk assessment influences project success

\section{Results from MRA}

Multiple Regression Analysis (MRA) was conducted to establish the relationship of risk assessment with project success by determining the influence of risk assessment on project success. The Regression results are presented in Table 6. It is shown that one measure (RA2) of risk assessment was found to be significant (i.e., $p=0.000<0.05$ ), making the largest significant contribution of 56\% (beta $=0.566$ ). The results in Table 7 show risk assessment explained 19\% $\left(\mathrm{R}^{2}=0.186\right)$ of the variance in project success at SMEs level. This suggested that risk assessment was not a good predicator of project success because of the low $\mathrm{R}^{2}$ achieved.

Table 6. Coefficients- Influence of risk assessment on project success

\begin{tabular}{|l|l|l|l|l|l|}
\hline \multirow{2}{*}{ Model } & \multicolumn{2}{|l|}{ Unstandardized } & Standardized & Sig. & Zero-order correlations \\
\cline { 2 - 4 } & B & Std. Error & Beta & & \\
\hline (Constant) & 18.836 & 0.394 & & 0.000 & \\
\hline RA1 & -0.057 & 0.151 & -0.044 & 0.706 & 0.246 \\
\hline RA2 & 0.794 & 0.158 & $\mathbf{0 . 5 6 6}$ & $\mathbf{0 . 0 0 0}$ & 0.398 \\
\hline RA3 & -0.268 & 0.157 & -0.221 & 0.090 & 0.153 \\
\hline RA4 & 0.038 & 0.171 & 0.027 & 0.826 & 0.210 \\
\hline RA5 & -0.005 & 0.141 & -0.004 & 0.973 & 0.107 \\
\hline
\end{tabular}

Table 7. Model summary- Influence of risk assessment on project success

\begin{tabular}{|l|l|l|l|l|}
\hline Model & $\mathrm{R}$ & $\mathrm{R}^{2}$ & Adjusted $\mathrm{R}^{2}$ & Std. Error of the Estimate \\
\hline & 0.431 & 0.186 & 0.163 & 1.34992 \\
\hline
\end{tabular}

However, the ANOVA results in Table 8 indicated that the model reached statistical significance at $p=0.000$ (i.e., $<0.05$ ). This indicated that project success was influenced by one measure (RA2) of risk assessment and that the influence was significantly different from the value of 7.997 ( $F$ value). Thus, the null hypothesis $\left(\mathrm{H} 1_{0}\right)$ that risk assessment does not influence project success could not be supported. This means that the hypothesis (H1) could not be rejected.

Table 8. ANOVA- Influence of risk assessment on project success

\begin{tabular}{|l|l|l|l|l|l|}
\hline & Sum of Squares & df & Mean square & F & Sig. \\
\hline Regression & 72.868 & 5 & 14.574 & 7.997 & 0.000 \\
\hline Residual & 318.900 & 175 & 1.822 & & \\
\hline Total & 391.768 & 180 & & & \\
\hline
\end{tabular}

The relationship between risk assessment and project success was found to be significant, indicating that risk assessment positively influenced project success. This finding was supported by the study of reference [37]; [28]; [38] where it was found that project risk assessments enables project risk responses and mitigation strategies used effectively and avoid project cost overrun, delays and ensure project completion within the specified period. In addition, reference [28] established that there is a positive impact on risk assessment and project planned budget. Likewise, the current result is supported by the study of reference [33] which indicated that risk assessment conducted, increases the project performance in achieving project set goals. These findings imply that SMEs project risk assessment should be done effectively by competent officers to identify project risk facing SMEs projects and achieve project performance and that given the high failure rates associated with construction projects, lack of prudent for organisations to improve their ability to manage their construction project risks lead to projects failure. The findings failed to concur with reference [27] who contradicts the findings by indicating that most SMEs project failed to assess risk measures leading to poor construction SMEs project performance in terms of timeliness, profitability, costs and 
project schedules. Another study contradicting the current findings is that of reference [39] although it was indicated that all risk management practices namely; risk identification, risk assessment, risk response planning, and risk monitoring and control are required for project performance and project success, it was statistically established that there is an insignificant relationship between risk assessment and project success, suggesting that risk assessment negatively influences project success. This result indicates that risk analysis practices should be limited to avoid a negative impact on project scheduled time and budget.

\section{Acknowledgements}

The authors wish to acknowledge the participation of small and medium contractors. Without their participation, this study would not have been possible. Our thanks further go to the University of Johannesburg for the financial support in conducting this study.

\section{Conclusion}

The main objective of the study was to determine the relationship of risk assessment with project success of small and medium construction enterprises to in Gauteng, South Africa. Through a questionnaire survey among SMEs respondents in Gauteng, it was found that there is a positive significant impact of project risk assessment on project success that risk assessment leads to success in construction projects of SMEs. The current finding provides guidance to contractors on the practical implementation of RA concerns for construction PS.

The study recommends that upper management of SME projects should increase the level of project risk assessment as it enhances the risk management activities. The study recommends that a further study should be carried out to investigate the effects of other risk management strategies on project performance of SMES not discussed in this study such as risk identification, risk responses, monitoring and review. A further study should be carried out to determine strategies that should be adopted to maintain the positive effects of risk management strategies on the project performance of construction SMEs.

\section{References}

[1] L.E. Boone, D.L. Kurtz. (2006). Contemporary Business, Thomson/South West Publishers, USA

[2] Y. Smit. (2012). A structured approach to risk management for South African SMEs, PhD thesis, Cape Peninsula-University of Technology, Cape Town, South Africa.

[3] McKinsey Global Institute, The world at work: Jobs, pay and skills for 3.8 billion people, June 2012.

[4] S. Ramlee, B. Berma. (2013). Financial gap in Malaysian small-medium enterprises: A supply-side perspective, South African Journal of Economic and Management Sciences, 16(5), Pretoria.

[5] R. Brown, N. Lee. (2014). Funding issues confronting high growth SMEs in the UK, ICAS, Edinburgh, UK.

[6] A. Rostami, J.Sommerville, I. Wong, C. Lee. (2015). Risk Management Implementation in Small and Medium Enterprises in the UK Construction Industry, Engineering, Construction and Architectural Management, 22(1): 91-107.

[7] W. Imbeah, S. Guikema. (2009). Managing construction projects using the advance programmatic risk analysis and management model, Journal of construction engineering and management, 135(8): 772-781.

[8] S. Chihuri, L. Pretorious. (2010). Managing risks for Success in a South African Engineering and Construction Project Environment, South African Journal of Industrial Engineering, 21(2):63-77.

[9] S. Shunmugam P.D. Rwelamila. (2014). An evaluation of the status of risk management in South African construction projects, Proceedings of the Project Management South Africa (PMSA) Conference, ISBN: 978-0-620-64562-1 29, 30 September and 1 October, Johannesburg, South Africa.

[10] G.Silvius, J. Tharp. (2013). Sustainability Integration for Effective Project Management. Business Science.

[11] X. Wang, J. Huang. (2006). The relationships between key stakeholders' project performance and project success: perceptions of Chinese construction supervising engineers, International Journal of Project Management 24, 253-260.

[12] M.M. Carvalho, J.R. Rabechini. (2015). Impact of risk management on project performance: the importance of soft skills, International Journal of Production Research, 53 (2): 321-340.

[13] S. Toor, S. Ogunlana. (2010). Beyond the iron triangle: stakeholder perception of key performance indicators (KPIs) for large-scale public sector development projects, International Journal of Project Management 28, 228-236.

[14] M.T Banki, S. Hadian, M. Niknam, I. Rafizadeh. (2009). Contractor selection in construction projects based on a fuzzy AHP method. Proceedings of the Annual Conference-Canadian Society for Civil Engineering.

[15] S.T. Ng, Z. Tang, K. Palaneeswaran. (2009). Factors contributing to the success of equipment-intensive subcontractors in construction, International Journal of Project Management, 27: 736-744. 
[16] J. Hinze, S. Thurman, A. Wehle. (2013). Leading indicators of construction safety performance. Safety Science, 51(1):23-28.

[17] J.S.Chou, A.D Pham.(2013).Project management knowledge of construction professionals: Cross-country study of effects on project success, Journal of Construction Engineering and Management, 139(11):04013015-1-04013015-15

[18] A. Collins, D. Baccarini. (2004). Project success-a survey, Journal of Construction Research, 5 (2): 211-231.

[19] U. Ojiako, E. Johansen, D. Greenwood. (2008). A qualitative re-construction of project measurement criteria, Industrial Management and Data Systems, 108 (3): 405-417.

[20] C M. Weninger, J.C. Huemann, L.F.M. Oliveira, F. Barros, E. Weitlaner. (2013). Experimenting with project stakeholder analysis: a case study. In: Silvius, A.J.G., Thap, J. (Eds.), Sustainability Integration for Effective Project Management. IGI Global.

[21] F.T. Berssaneti, M. M Carvalho. (2015).Identification of variables that impact project success in Brazilian companies, International Journal of Project Management, 33: 638-649

[2] D.K Ahadzie, D.G Proverbs, P.O. Olomolaiye. (2008). Critical success criteria for mass house building projects in developing countries, International Journal of Project Management, 26: 675-687

[23] E.Lam, A.. Chan, D. Chan. (2008). Determinants of successful design-build projects, Journal of Construction Engineering and Management 134 (5): 333-341.

[24] A. L. C. Roelen, M. B Klompstra. (2012). The challenges in defining aviation safety performance indicators. Preprint for PSAM II and ESREL, 25-29 June, 2012, Helsinki: Finland

[25] J.S Chou, J.G Yang. (2012). Project management knowledge and effects on construction project outcomes: an empirical study, Project Management Journal, 43 (5): 47-67.

[26] D.P Dingsday, H.C Biggs, D. Cipallo. (2008). Safety effectiveness indicators (SEIs): Measuring construction industry performance. Proceedings Third International Conference of the Cooperative Research Centre (CRC) for Construction Innovation-Clients Driving Innovation: Benefitting from Innovation, Gold Coast, Australia.

[27] R. Roque, Y. de Carvalho. (2013). The impact of project risk management, assessment of risks on project performance in Brazillian Vendor companies, International Journal of Project Management, 21 (2):97-105.

[28] H.H. Shibly, B.M. Louzi, M.A. Hiassat. (2013). The impact of risk management on construction projects success from the employees' perspective, Interdisciplinary Journal of Contemporary Research in Business, 5(4):12-43.

[29] J. Zeng, N. J. Smith. (2007). Application of a Fuzzy Based Decision Making Methodology to Construction Project Risk Assessment, International Journal of Project Management, 25(6):589-600.

[30] S. El-Sayegh (2008). Risk Assessment and Allocation in the UAE Construction, International Journal of Project Management, 26 (4):431-438

[31] P. Lee-Anne, Bed (Hons). (2007). The Impact of Risk Management on the Changing Nature of Principal's Work, PhD Thesis, Queensland University of Education, Australia.

[32] A. Karimi, N. Mousavi., S. Mousavi, S. Hosseini. (2010). Risk Assessment Model Selection in Construction Industry, Expert Systems with Applications, 38 (2): 9105-9111.

[3] P.K. Naidoo. (2012). The effect of risk management on the success of a project. Master thesis, Faculty of engineering and the built environment, University of Johannesburg, Johannesburg, South Africa.

[34] C. Zaiontz. (2014). Real statistics using excel: Cronbach"s alpha. Word Press Online.

[35] J. Pallant. (2013). SPSS survival manual: A step by step guide to data analysis using IBM SPSS. 5th edition. Allen and Unwin, Australia.

[36] J.F. Hair, W.C. Black, J.B. Babin, R.E. Andersen, R.I Taham. (2006) Multivariate data analysis, 6thedition. Upper Saddle River, New Jersey: Pearson/Prentice Hall.

[37] E. Kinyua, Ogalloah, D.K Mburu. (2015). Effect of risk management strategies on project performance of small and medium information communication technology enterprises in Nairobi, Kenya, International Journal of Economics, Commerce and Management, 3 (2): 1-30

[38] R Morledge, A. Smith, D.T. Kashiwagi. (2006). Risk. In Building Procurement. Oxford: Blackwell. Mugenda

[39] D. Pimchangthong, V. Boonjing. (2017). Effects of risk management practices on it project success, Management and Production Engineering Review, 8 (1): 30-37 